\title{
À sombra do aborto: 0 debate social sobre a anticoncepção de emergência na mídia impressa brasileira (2005-2009)*
}

Rozana Aparecida de Souza ${ }^{1}$

Elaine Reis Brandão²

SOUZA, R.A.; BRANDÃO, E.R. In the shadow of abortion: the social debate on emergency contraception in the Brazilian press (2005-2009). Interface - Comunic., Saude, Educ., v.16, n.40, p.161-75, jan./mar. 2012.

This social-anthropological study discusses the central premises of the social debate on emergency contraception (EC) in Brazil, through analyzing 131 texts published in the newspapers Folha de S. Paulo (São Paulo) and O Globo (Rio de Janeiro) between 2005 and 2009, guided by the keywords: morning-after pill, emergency contraception and EC. The Catholic Church and Ministry of Health were the main interlocutors, identified through discourse based on war metaphors consonant with public health terminology. These texts poorly reproduced the arguments defending sexual and reproductive rights. The Catholic Church's contrary positioning was based on biomedical arguments that consider EC to be an abortion method because it is used postcoitally, thereby equating EC to misoprostol (Cytotec) and the RU486 pill. The Ministry of Health and professionals argued that EC may help to avoid unsafe abortions. However, its mechanism of action was not well discussed, such that abortion became the central topic.

Keywords: Contraception postcoital. Abortion. Sexual and reproductive rights. Healthcare services.
Trata-se de pesquisa socioantropológica que discute premissas centrais do debate social sobre a Anticoncepção de Emergência ( $A E)$ no Brasil, mediante análise de 131 textos publicados nos jornais Folha de S. Paulo (SP) e O Globo (RJ), de 2005 a 2009, orientada pelos descritores: pílula do dia seguinte, contracepção de emergência e AE. A Igreja Católica e o Ministério da Saúde são os principais interlocutores, identificados por um discurso baseado em metáforas bélicas, consoante à terminologia da saúde pública. Os textos pouco reproduzem argumentos de defesa dos direitos sexuais e reprodutivos. posicionamento contrário da Igreja Católica baseia-se em argumentos biomédicos que consideram o método abortivo por ser usado pós-coito, equiparando a $\mathrm{AE}$ ao misoprostol (Cytotec) e à pílula RU486. O Ministério da Saúde e profissionais defendem que a AE pode evitar abortos inseguros, mas seu mecanismo de ação não é bem discutido, e o tema aborto termina sendo central.

Palavras-chave: Anticoncepcionais pós-coito. Aborto. Direitos sexuais e reprodutivos. Serviços de saúde.
"Elaborado com base em Brandão (2008); pesquisa financiada pelo Programa "Jovem Cientista do Nosso Estado 2008" e Souza (2010). ${ }^{1}$ Instituto de Estudos em Saúde Coletiva / Universidade Federal do Rio de Janeiro (IESC) UFRJ);. Praça Jorge Machado Moreira, 100, Cidade Universitária, Ilha do Fundão, UFRJ. Telefones: 21-25989274 / 21-2598- 9271. rozanade@uol.com.br ${ }^{2}$ Departamento de Medicina Preventiva, Instituto de Estudos em Saúde Coletiva, Universidade Federal do Rio de Janeiro. 


\section{Introdução}

A Anticoncepção de Emergência (AE) é um método contraceptivo pós-coito que começou a ser estudado nas décadas de 1960-70 pelo médico canadense Albert Yuzpe, como resposta médica às consequências da violência sexual (Dides Castillo, 2006; Martin, 2004). Sua eficácia é conhecida há mais de trinta anos (Costa et al., 2008; Figueiredo, 2004). No cenário nacional, esse método foi reconhecido pelas normas de planejamento familiar do Ministério da Saúde em 1996 (Brasil, 1996).

$\mathrm{O}$ uso da $\mathrm{AE}$ no Brasil vem ocorrendo há anos em ambientes restritos, e não constitui prática sistematizada (Osis et al., 2006; Hardy et al., 2001). Ao longo da última década, o método ganhou visibilidade, e é utilizado pelas mulheres, nem sempre com acompanhamento médico, adquirido em farmácias, sem necessidade de receita médica. Dados da Pesquisa Nacional de Demografia e Saúde da Criança e da Mulher (PNDS) de 2006 (Brasil, 2008a) apontam esse contraceptivo como o terceiro método mais usado entre as mulheres não unidas e sexualmente ativas, e o quinto entre as mulheres unidas.

Análises de documentos sobre a AE apontam avanços no âmbito da legislação em saúde para a utilização desse método, os quais permitem oficialmente reconhecê-lo no país como alternativa contraceptiva em situações emergenciais, além dos casos de violência sexual. O levantamento da literatura nacional e internacional suscita questões referentes à não-incorporação dessas normas nas práticas cotidianas dos serviços de saúde, e revela representações sociais difíceis de serem revertidas em pouco tempo (Souza, Brandão, 2009).

Ocorre, na sociedade brasileira, um debate, expresso na mídia, sobre o modo de ação da $A E$, seu potencial (não)abortivo, sua distribuição pelos municípios e serviços de saúde. Às vezes, tal debate ganha o tom passional que marca a discussão atual sobre o aborto no Brasil, embora pesquisas científicas comprovem que esse método não é abortivo (Drezett, 2009; Brasil, 2006; Faúndes, Barzellato, 2004). Da mesma forma que ocorre com o aborto, existem dois interlocutores influentes que conquistam espaço no debate público sobre a $\mathrm{AE}$, como fontes jornalísticas comumente acionadas: a Igreja Católica e o Estado, representado pelo Ministério da Saúde (MS).

Segundo Dides Castillo (2006), quando se fala de um debate público sobre a $A E$, tem-se à frente um cenário em que a mídia é o centro e atua como intermediadora das vozes dos atores dos discursos vigentes. A imprensa simultaneamente altera os significados da vida para os sujeitos e reflete o que a sociedade vivencia (Lemos, 2006; Lupton, 1994, 1992).

Pesquisas identificaram a importância da mídia para a democratização das informações sobre $A E$ (Díaz et al., 2003a, 2003b; Hardy et al., 2001). Valores e conceitos veiculados pela mídia podem se transformar em preconceitos, desafios e dificuldades no uso da AE. A existência de lacuna, no campo das pesquisas nacionais sobre saúde reprodutiva, referente ao tema da $A E$, justificou a realização de um estudo que analisou o debate social sobre o método veiculado na mídia, no período de 2005 a 2009, em dois jornais impressos de grande circulação: O Globo e a Folha de S. Paulo (FSP). Foram identificados: as características da cobertura jornalística; a fonte das matérias; o destaque dado; os atores envolvidos; os argumentos em jogo; e os principais eventos que determinaram a cobertura jornalística.

O tratamento dado ao tema não se vincula à questão da violência sexual, que comumente gera o debate sobre a AE. O método é abordado no conjunto dos contraceptivos disponíveis, e pode ser usado, com orientação médica, em situações emergenciais, que não se restringem ao estupro.

\section{Metodologia}

Pesquisa socioantropológica, cuja técnica de coleta de dados foi a análise de textos de jornais (Minayo, 2008; Victora, 2000; Becker, 1997). Houve seleção, classificação e análise dos textos publicados nos jornais Folha de S. Paulo e O Globo, no período de 01/01/2005 a 31/12/2009, orientadas pelos descritores: anticoncepção de emergência, contracepção de emergência e pílula do dia seguinte. Esses jornais foram selecionados por apresentarem as maiores tiragens dentre os jornais 
impressos no Brasil (Harenza, 2008). O ano de 2005 foi escolhido como marco inicial para coleta dos dados, por ter sido quando o MS ampliou a distribuição da AE em aproximadamente 50\%, com o objetivo de distribuir a pílula a todos os municípios brasileiros (Suwwan, 2005).

Foram selecionados 158 textos que apresentavam, pelo menos, um dos descritores citados, independentemente da seção, do gênero jornalístico e do tema central abordado pelo texto. Após a primeira leitura, optou-se por excluir 27 textos, que exigiam análise diferenciada, devido às especificidades das questões que tratavam: 22 textos destinavam-se ao público jovem (questões de vestibular, cartas) e os demais eram sobre programas de TV e resenha de um romance.

O roteiro de coleta das informações dos 131 textos analisados privilegiou os itens: data; autor; título; seção; número de linhas; origem e fontes de informação; gênero jornalístico; abordagem principal; e características da fonte.

Os dados coletados são apresentados de forma descritiva acerca do perfil dos textos levantados e, também, de como as representações sociais que circulam na sociedade sobre a AE são retratadas pela mídia impressa, e formatam ideias, opiniões, julgamentos e posições morais.

\section{Resultados}

A Folha de S. Paulo apresentou 91 textos e O Globo, quarenta textos, entre notícias, artigos, cartas do leitor, editoriais, chamada na capa, entrevistas, notas de colunista e destaques.

Tabela 1. Textos analisados na Folha de S. Paulo e em O Globo, 2005 a 2009

\begin{tabular}{|c|c|c|c|c|c|c|}
\hline \multirow{3}{*}{ Ano } & \multicolumn{4}{|c|}{ Jornal } & \multirow{2}{*}{\multicolumn{2}{|c|}{ Total }} \\
\hline & \multicolumn{2}{|c|}{ Folha de S. Paulo } & \multicolumn{2}{|c|}{ O Globo } & & \\
\hline & $\mathrm{N}^{\circ}$ & $\%$ & $\mathrm{~N}^{\circ}$ & $\%$ & $\mathrm{~N}^{\circ}$ & $\%$ \\
\hline 2005 & 33 & 36,3 & 20 & 50,0 & 53 & 40,5 \\
\hline 2006 & 10 & 11,0 & 6 & 15,0 & 16 & 12,2 \\
\hline 2007 & 15 & 16,5 & 6 & 15,0 & 21 & 16,0 \\
\hline 2008 & 16 & 17,6 & 6 & 15,0 & 22 & 16,8 \\
\hline 2009 & 17 & 18,7 & 2 & 5,0 & 19 & 14,5 \\
\hline Total & 91 & $100 \%$ & 40 & $100 \%$ & 131 & $100 \%$ \\
\hline
\end{tabular}

Fonte: Folha de S. Paulo e O Globo. Edições impressas de 2005 a 2009.

\section{Gênero jornalístico}

O gênero jornalístico preponderante do material levantado é a notícia, seguida de cartas do leitor. Na Folha de S. Paulo, 53,84\% dos textos são notícias e $24,18 \%$, cartas do leitor. Em O Globo, as notícias representam $52,50 \%$ do total de textos, e as cartas do leitor correspondem a $25 \%$.

Tabela 2. Gênero jornalístico na Folha de S. Paulo por ano, 2005 a 2009

\begin{tabular}{c|c|c|c|c|c|c|c|c|c|c|c|c}
\hline $\begin{array}{c}\text { Gênero } \\
\text { jornalístico }\end{array}$ & $\mathbf{2 0 0 5}$ & $\%$ & $\mathbf{2 0 0 6}$ & $\%$ & $\mathbf{2 0 0 7}$ & $\%$ & $\mathbf{2 0 0 8}$ & $\%$ & $\mathbf{2 0 0 9}$ & $\%$ & Total & $\%$ \\
\hline Notícia & 15 & 45,46 & 09 & 90,00 & 05 & 33,33 & 08 & 50,00 & 12 & 70,60 & 49 & 53,84 \\
Cartas do leitor & 12 & 36,36 & - & - & 04 & 26,66 & 05 & 31,25 & 01 & 05,88 & 22 & 24,18 \\
Artigo & 02 & 06,06 & 01 & 10,00 & 03 & 20,00 & - & - & 03 & 17,64 & 09 & 09,90 \\
Editorial & 01 & 03,03 & - & - & 01 & 6,67 & 01 & 6,25 & - & - & 03 & 03,30 \\
Entrevista & - & - & - & - & 01 & 6,67 & - & - & - & - & 01 & 01,09 \\
Nota colunista & 02 & 06,06 & - & - & - & - & - & - & - & - & 02 & 02,19 \\
Capa & 01 & 03,03 & - & - & 01 & 6,67 & 02 & 12,50 & 01 & 05,88 & 05 & 05,50 \\
\hline Total & 33 & 100 & 10 & 100 & 15 & 100 & 16 & 100 & 17 & 100 & 91 & 100 \\
\hline
\end{tabular}

Fonte: Folha de S. Paulo. Edições impressas de 2005 a 2009. 
Tabela 3. Gênero jornalístico em O Globo por ano, 2005 a 2009

\begin{tabular}{c|c|c|c|c|c|c|c|c|c|c|c|c}
\hline $\begin{array}{c}\text { Gênero } \\
\text { jornalístico }\end{array}$ & $\mathbf{2 0 0 5}$ & $\%$ & $\mathbf{2 0 0 6}$ & $\%$ & $\mathbf{2 0 0 7}$ & $\%$ & $\mathbf{2 0 0 8}$ & $\%$ & $\mathbf{2 0 0 9}$ & $\%$ & Total & $\%$ \\
\hline Notícia & 08 & 40,00 & 04 & 66,66 & 04 & 66,66 & 03 & 50,00 & 02 & 100 & 21 & 52,50 \\
Cartas do leitor & 09 & 45,00 & - & - & - & & 01 & 16,66 & - & - & 10 & 25,00 \\
Artigo & 02 & 10,00 & 01 & 16,67 & 01 & 16,67 & - & - & - & - & 04 & 10,00 \\
Editorial & - & - & - & - & - & - & - & - & - & - & - & - \\
Entrevista & - & - & - & - & - & - & - & - & - & - & - & - \\
Nota colunista & 01 & 05,00 & - & - & - & - & 02 & 33,34 & - & - & 03 & 07,50 \\
Destaque & - & & 01 & 16,67 & 01 & 16,67 & - & - & - & - & 02 & 05,00 \\
\hline Total & 20 & 100 & 06 & 100 & 06 & 100 & 06 & 100 & 02 & 100 & 40 & 100 \\
\hline
\end{tabular}

Fonte: O Globo. Edições impressas de 2005 a 2009.

Em O Globo, a AE não foi texto de capa ao longo dos anos monitorados. Esse assunto ganhou espaço duas vezes na seção Destaques. Na Folha de S. Paulo, a AE apareceu como chamada na capa por cinco vezes. O método foi tema de editoriais apenas no jornal Folha de $S$. Paulo (três vezes). Esses editoriais apresentam teor favorável à distribuição e ao uso da $A E$, e fazem ressalvas às interferências da hierarquia católica no âmbito das políticas públicas de saúde reprodutiva.

\section{Principais eventos que provocaram a cobertura jornalística}

A cobertura jornalística relacionada à AE do ano 2005 é marcada pelos eventos: decisão do prefeito César Maia de distribuir a $A E$, atendendo às diretrizes do MS e, em seguida (após pressão do bispo católico do Rio de Janeiro), de suspender a distribuição; regulamentação, pelo MS, da distribuição da $\mathrm{AE}$ a todos os serviços públicos de saúde; decisão do MS de financiar $100 \%$ dos métodos contraceptivos; projeto de lei, em tramitação na Câmara de Deputados, para aprovação do aborto; veto à $A E$ pelos vereadores nos municípios de São José dos Campos e de Jacareí (SP).

Textos de 2006 apresentam os eventos: posicionamento do presidente Felipe Calderón contra o método na campanha eleitoral mexicana; posicionamento da presidente chilena, Michele Bachelet, favorável à $A E$; liberação da venda de $A E$ sem receita médica nos $E U A$; distribuição da $A E$ no carnaval de Salvador.

Em 2007, o posicionamento do Ministro da Saúde a favor da suspensão da necessidade de prescrição médica para o uso da AE marca a cobertura jornalística. A distribuição da $A E$, pelas secretarias municipais de saúde, nos carnavais de Olinda, Paulista e Recife, em Pernambuco, determina publicação de textos sobre o método no ano de 2008.

No ano de 2009, os eventos noticiados foram: venda da AE em bar na cidade de Maceió, Alagoas; crescimento do número de abortos com amparo legal; pesquisas realizadas em São Paulo com adolescentes e profissionais de saúde sobre como usar a $\mathrm{AE}$; pesquisa com adolescentes de escolas públicas de Pernambuco sobre o uso do método; impacto da AE na prevenção à infecção pelo HIV; eleições para a presidência do Chile e vitória do candidato de direita Sebastian Piñera; distribuição da AE em farmácias municipais localizadas em estações de metrô de São Paulo; ações de reforço no planejamento familiar na cidade do Rio de Janeiro; ampliação da distribuição de preservativos e $A E$ pelo MS.

\section{Características das fontes dos textos}

No jornal Folha de S. Paulo, foram coletados 26 textos que apresentam conflitos entre grupos favoráveis e grupos contrários ao método. Seis textos apontam possíveis consequências negativas do uso da $A E$, e dez textos apresentam uma abordagem que assinala avanços e novas direções da história 
da política de direitos reprodutivos. Ainda, quatro textos da Folha de S. Paulo indicam restrições ou riscos no uso da $A E$, sobretudo por adolescentes.

Em O Globo, 14 textos apresentam conflito entre grupos favoráveis e contrários ao uso da AE. Oito textos ressaltam avanços no campo dos direitos reprodutivos, e dez referem-se a questões éticas acerca dos dilemas que envolvem o uso da AE (é abortiva ou não).

Quanto às fontes de informação dos textos, no âmbito legislativo, executivo e judiciário, ministros de Estado e secretários de saúde são os atores mais frequentes, tanto na Folha de S. Paulo (17 textos) quanto em $O$ Globo (oito textos). Já no âmbito da ciência e medicina, por 16 vezes cientistas foram fontes da informação no jornal Folha de $S$. Paulo, e O Globo recorreu cinco vezes a médicos e hospitais.

Interlocutores católicos aparecem em 15 textos como fonte de informação na Folha de S. Paulo, e 05 no jornal O Globo. Treze textos da Folha de S. Paulo apresentam grupos organizados contrários à $A E$ como fonte de informação.

Identifica-se, nos textos da Folha de S. Paulo, um embate: 42 textos apresentam vinculação com direito, ética e bioética; 24 , vinculação disciplinar com moral, e 26, com ciências médicas e biológicas. Em O Globo, 12 textos têm vinculação com direito, ética e bioética; nove, com moral, e seis, com ciências médicas e biológicas.

\section{Representações sociais da anticoncepção de emergência nos jornais Folha de S. Paulo e O Globo: argumentos, interlocutores e conflitos}

\section{Anticoncepção de emergência e aborto}

Nos textos examinados, há duas representações que aparecem com frequência e que se contrapõem: a AE como método legítimo, como mais uma alternativa para prevenir gravidez, caso haja falha na contracepção regular, esquecimento, relação sexual desprotegida e na tentativa de evitar um eventual aborto inseguro; e a representação da $\mathrm{AE}$ como método abortivo.

$O$ argumento da AE como método abortivo é utilizado por setores da Igreja Católica e por sujeitos e instituições a ela ligados. Interlocutores desse discurso, além de religiosos (padres e bispos) identificados nos textos, foram: Provida Família (entidade católica de defesa dos direitos da família); Conferência Nacional dos Bispos do Brasil (CNBB); Comissão de Bioética da CNBB; vereadores, prefeitos e deputados (estaduais e federais) ligados ao catolicismo; instituição católica de Ensino Superior; médicos; Pastoral da Saúde; Comissão Episcopal Pastoral para a Vida e a Família - CNBB; Movimento Nacional em Defesa da Vida Brasil sem Aborto; Núcleo Fé e Cultura da PUC/SP; Instituto de Defesa da Vida da Ação Familiar. Vale ressaltar que nenhuma outra religião foi fonte de informações para os textos analisados.

Os interlocutores da representação da AE como uma maneira de evitar a gravidez e o aborto inseguro foram: representantes do MS e das secretarias estaduais e municipais de saúde; vereadores; prefeito de São José dos Campos (PSDB/SP); profissionais da área da saúde, militantes de grupos feministas (SOS Corpo/PE, Instituto Patrícia Galvão/SP, Católicas pelo Direito de Decidir, Jornadas Brasileiras pelo Aborto Legal e Seguro); Conselho Federal de Medicina (CFM); mulheres com atuação em movimentos populares de São Paulo; diretora do hemisfério ocidental da Federação Internacional de Planejamento Familiar (IPPF); Federação Brasileira das Sociedades de Ginecologia e Obstetrícia (Febrasgo); assessor do Consórcio Latino-americano da Anticoncepção de Emergência (CLAE) e consultor do MS; professora da UnB; editoriais e colunista do jornal Folha de S. Paulo.

No cenário internacional, os interlocutores adversos à difusão da $\mathrm{AE}$ foram: presidente da Conferência Episcopal Chilena; líderes do cenário político norte-americano; Conferência de Bispos Católicos Americanos; presidente do México, Felipe Calderón.

Por sua vez, os interlocutores favoráveis ao método em contexto internacional são: o Conselho dos Direitos Reprodutivos dos EUA; grupos feministas americanos (não definidos no texto da FSP); Conselho Americano de Direitos Reprodutivos; Instituto Alan Guttmacher (EUA); médicos norteamericanos; presidente do Chile, Michele Bachelet. 
Exemplo de discurso da $\mathrm{AE}$ como método abortivo no cenário internacional é a reação da Conferência dos Bispos Católicos Americanos contra a liberação da venda do método sem prescrição médica para mulheres maiores de 18 anos nos EUA: "a pílula, seja para adultos ou menores de idade, causa aborto ao impedir a implantação do óvulo fecundado na parede do útero" (EUA..., 2006).

Em textos sobre aborto e sobre interrupção da gestação de fetos anencéfalos, quando a fonte da informação é a Igreja Católica ou setores a ela ligados, o assunto da AE está presente, sob o argumento de ela ser "abortiva".

Notícias veiculadas pelos jornais analisados, sobre a decisão dos vereadores da Câmara Municipal de São José dos Campos (SP) de vetarem a distribuição da AE pelos serviços públicos de saúde, ressaltam o argumento usado pelos legisladores: "o medicamento é abortivo e, por isso, inconstitucional, já que o aborto é ilegal no país" (Saúde..., 17/05/2005). Para os vereadores, "a intenção da Câmara é preservar a vida" (Saúde..., 30/04/2005).

$\mathrm{O}$ argumento da $\mathrm{AE}$ como um método para evitar o aborto, quando corretamente usada, dá o tom para os textos com teor favorável a ela. Texto de 06/10/05, de O Globo, traz o exemplo dos EUA: a AE reduziu o número de abortos em 110 mil, entre os anos de 1994 e 2000.

Segundo notícia da Folha de S. Paulo, de 23/01/09, sobre o aumento de abortamentos em casos previstos em lei, apesar do aumento das denúncias dos casos de violência sexual, uma professora da UnB declara que "houve redução significativa dos casos de interrupção da gravidez por estupro após a distribuição da pílula do dia seguinte".

O debate sobre a pílula pós-coital ser abortiva ou não provocou situações de crise para políticos dos EUA, do Chile, México e Brasil, que se posicionavam em relação ao método. Aqueles que se posicionaram a favor do método enfrentaram conflitos com representantes da hierarquia católica e com setores da sociedade a ela vinculados. Os políticos que se manifestaram contrários à distribuição da AE sofreram embates e críticas por parte de grupos da sociedade, dentre eles: entidades ligadas ao movimento feminista, profissionais de saúde e políticos que se posicionavam favoravelmente ao método.

Exemplo de como o método pode ocasionar "problemas" para políticos é o caso da presidente do Chile, que se posicionou favoravelmente à distribuição da AE para adolescentes: "a questão da pílula mereceu repúdio dos conservadores porque, com a iniciativa do governo, menores a partir dos 14 anos poderão recebê-la sem o consentimento dos pais, o que antes era obrigatório" (Bachelet..., 2006). Para a Conferência Episcopal Chilena, esse método "representa um problema ético que atenta contra a família chilena" (Chega..., 2006).

A polêmica da distribuição da AE para adolescentes no Chile traz à tona o debate sobre a sexualidade na adolescência. Os resultados sobre AE e adolescência serão apresentados em outro artigo.

\section{Anticoncepção de emergência: riscos de torná-la um método de uso regular}

Transformar a AE em método de uso regular, ou seja, tornar seu uso abusivo, é preocupação constante de médicos, representantes da Associação Brasileira Interdisciplinar de Aids (ABIA), do CLAE, do MS, do CFM, da Febrasgo, de secretarias municipais de saúde, de representantes da Igreja Católica e de setores conservadores a ela ligados.

O argumento de que a AE é de uso circunstancial e deve ser o "último recurso para evitar a gravidez" marca os textos com teor favorável e contrário a ela. Os interlocutores contrários à $\mathrm{AE}$ alegam que as mulheres não são capazes de usar corretamente o método, que abusariam de seu uso.

Profissionais de saúde com posicionamento favorável à $A E$ ressaltam cautela no uso do método: "em situações emergenciais". Depoimento da coordenadora da Área de Saúde da Mulher da Secretaria Municipal de Salvador (BA), em notícia sobre distribuição da AE no carnaval soteropolitano, exemplifica esse argumento: 
Queremos deixar bem claro que a pílula do dia seguinte é a última opção que deve ser utilizada pelas mulheres. O mais recomendável é a utilização de métodos contraceptivos mais eficazes, como a camisinha, as pílulas anticoncepcionais orais e injetáveis e o DIU [...]. A campanha é muito clara e revela que somente o sexo seguro protege os seus praticantes de doenças, como a Aids [...]. (Carnaval..., 2006)

Notícia de 21/01/09 da Folha de S. Paulo, sobre venda da AE em bar de Maceió (AL), traz um depoimento da farmacêutica da Vigilância Sanitária do município, que aponta a preocupação "com a banalização da venda" do método e ressalta que ele não deve ser "usado de forma rotineira".

Dados de pesquisa realizada pelo MS sobre o comportamento sexual do brasileiro apontam que a prática do sexo casual cresceu, "mas o uso da camisinha caiu" (FSP, 19/06/09, p.C1). Para o psiquiatra do Hospital das Clínicas de São Paulo: "Com coquetel anti-Aids e pílula do dia seguinte para evitar gravidez, o pessoal tem tomado menos cuidado. Há uma falsa sensação de segurança" (FSP, 19/06/09, p.C1).

\section{Anticoncepção de emergência na seção Cartas do Leitor}

Foram levantadas 31 cartas dos leitores, 21 no jornal Folha de S. Paulo e dez em O Globo. A maioria das cartas publicadas é assinada por mulheres $(67,74 \%)$, o que equivale, em O Globo, a $70 \%$ das cartas e, na Folha de S. Paulo, a 66,67\%.

Seis cartas de $O$ Globo têm conteúdo vinculado disciplinarmente a direito e ética, e quatro são vinculadas a uma moral baseada em argumentos cristãos. A Folha de S. Paulo apresenta: dez cartas com vinculação disciplinar ligada ao direito e à ética, seis estão vinculadas às disciplinas de ciências médicas e biológicas, e cinco são vinculadas a moral (debate baseado em categorias de uma moral cristã).

As representações da AE presentes nas cartas dos leitores publicadas nos jornais Folha de $S$. Paulo e O Globo são: AE como método abortivo; um método que provoca o exercício sem controle da sexualidade, sobretudo por adolescentes; o método como possibilidade de prevenir gestações imprevistas e aborto, significando um avanço nas políticas de planejamento familiar do MS; outro argumento identificado é a pílula como meio que serve para evitar a gravidez adolescente de classes populares (controle populacional).

Uma carta reprovando decisão do prefeito César Maia (PFL/RJ) de proibir a distribuição da $A E$ no Rio de Janeiro remete à ideia do método como prevenção à gravidez na adolescência: "A pílula do dia seguinte é mais uma forma de evitar a gravidez desenfreada e impensada de adolescentes carentes. [...] Passo positivo para a natalidade em condições muito desfavoráveis" (Saúde..., 29/01/2005).

Carta da leitora identificada como "coordenadora da área técnica de saúde da mulher da Secretaria de Atenção à Saúde do Ministério da Saúde (Brasília/DF)" exemplifica o discurso de que o método seria um meio para evitar gravidez imprevista e aborto, parte do planejamento familiar. A carta comenta o texto, de 15/03, Saúde ataca crítico da pílula do dia seguinte:

O planejamento familiar possibilita o espaçamento entre gravidezes e evita a realização de abortamentos inseguros ou legais, essa ação de saúde é fundamental para a redução da morte materna, que se encontra em altos patamares em nosso país. (Pílula..., 2005)

O discurso da AE como método abortivo aparece na seção Carta do Leitor, na opinião de médico ginecologista-obstetra de São Paulo:

[...] parece-me óbvio que essa medicação é, na maioria das vezes, francamente abortiva, pois, como o nome diz, geralmente é tomada várias horas após o ato sexual e impede a nidação do ovo fecundado (embrião) na parede uterina. O que ocorre é a eliminação do embrião, o que se caracteriza como um abortamento subclínico. (Pílula..., 2005) 
Várias cartas do leitor sobre a decisão da Câmara de Vereadores de São José dos Campos (SP) estão publicadas no jornal Folha de S. Paulo, algumas com teor favorável à decisão dos vereadores (quatro cartas), outras contrárias à decisão (três cartas). Como exemplo de argumento que defende a decisão dos vereadores, há: "Que idéia mais absurda essa de tentar matar um problema matando seres inocentes" (Dia Seguinte, 08/05/05), e ainda:

Além de a pílula do dia seguinte ser abortiva, o propalado planejamento familiar defendido pelo Ministério da Saúde busca suprir a ineficiência do governo em resolver os seus problemas administrativos e econômicos. O governo querer acabar com os pobres porque não consegue oferecer boas condições para que nasçam e vivam com dignidade é uma solução simplesmente covarde. (Solução..., 2005)

Duas cartas apresentam argumentos contrários à decisão da câmara:

O veto em São José dos Campos vai afetar apenas as mulheres de baixa renda, as que precisam ganhar o medicamento. São elas as que mais necessitam, que não possuem a mínima condição financeira e mental para arcar com uma gravidez indesejada. (DIA Seguinte, 11/05/05)

Possibilitar a obtenção do maior número possível de meios de planejamento familiar pela população carente é uma atitude louvável do governo federal. (DIA Seguinte, 23/05/05)

A ação civil pública encaminhada pelo MS à Justiça Federal, a fim de revogar o veto à $A E$ no município de São José dos Campos, também recebeu comentários na seção de cartas do leitor.

A Câmara Municipal de Vereadores de Jacareí/SP também se posicionou contrariamente à AE. Esse fato foi comentado por uma leitora, que se identificou como "integrante das Jornadas Brasileiras pelo Direito ao Aborto Legal e Seguro (João Pessoa, PB)":

Lamento a posição dos Vereadores [...]. Esses cidadãos que se ocupam de fazer leis para proibir uma política pública de saúde que visa prevenir a gravidez indesejada são os mesmos que condenam as mulheres que fazem aborto. (FSP, 17/07/05, p. A3)

Essas cartas, juntamente com os demais textos editados pela mídia impressa, apontam como o debate sobre a AE no cenário nacional carece de ser problematizado.

\section{Discussão}

Em comparação com a Folha de S. Paulo, o jornal O Globo destina pouco espaço em suas edições para textos sobre $A E$, e apresenta discussão menos plural na abordagem do tema. A Folha de S. Paulo traz uma perspectiva mais abrangente sobre o método, abre espaço a distintos interlocutores. Com exceção da distribuição da AE no carnaval de Salvador, (BA), em 2006, não há outro evento nacional ligado ao método publicado nos jornais.

Comumente, o assunto $\mathrm{AE}$ apareceu vinculado à discussão do aborto. Entidades ligadas ao movimento pelo direito ao aborto têm número significativo de cartas (quatro) publicadas na Folha de S. Paulo.

Manchetes são características importantes das reportagens, proporcionam referência ao conteúdo dos textos, expressam o tema principal.

Muitas vezes, são a única parte do texto lida pelo leitor (Lupton, Mclean, 1998). Algumas manchetes dos textos publicados chamam a atenção pela remissão ao conteúdo: O Brasil do dia seguinte; Dia Seguinte: Governo não tem dados sobre pílula em 2007; Polêmica do dia seguinte. Nesses títulos, há a ideia de uma nação imediatista, de um governo sem controle sobre suas ações. Muitos títulos indicam que a distribuição da AE será descontrolada ou generalizada: Juiz manda 
${ }^{3}$ A Área Técnica da Saúde da Mulher do MS, por meio da Portaria $\mathrm{n}^{\circ}$ 1.044, de 05/05/2010 incluiu o medicamento misoprostol na Relação Nacional de Medicamentos Essenciais de 2010 (Rename 2010) distribuir pílula do dia seguinte; Salvador dá pílula do dia seguinte à foliona. Certos títulos fazem referência à noção de liberdade, autonomia, exercício de um direito e laicidade do Estado brasileiro: Pelo direito à opção; A religião não pode ditar as normas da vida.

Há manchetes que trazem à tona noções equivocadas sobre o método: Ministro amplia distribuição gratuita da pílula do dia seguinte: plano prevê que medicamento seja usado para evitar gravidez indesejada até em relações estáveis. Cabe ressaltar que a AE deve ser usada em situações em que há falha ou esquecimento de métodos contraceptivos, independentemente de esse fato ocorrer em relações sexuais entre parceiros ocasionais ou em relacionamentos estáveis.

Tanto na Folha de S. Paulo quanto no jornal O Globo, um número elevado de textos indica conflito entre grupos favoráveis e contrários ao método. Por vezes, o discurso das ciências médicas e biológicas atende aos interesses da hierarquia católica, declarando o método como abortivo.

\section{O posicionamento da Igreja Católica frente à anticoncepção de emergência: "à sombra do aborto"}

Argumentos do discurso católico sobre $A E$, apresentado pela mídia impressa, são: defesa da vida e proibição total ao aborto e aos métodos contraceptivos artificiais. A Igreja hostiliza qualquer forma de controle da fecundidade, com exceção dos métodos naturais (Humanae Vitae, 1968).

A representação da $A E$ como abortiva define o tom do discurso contrário publicado nos jornais. O debate católico contra o aborto está baseado no conceito de que a vida tem início na concepção e no Estatuto Moral do Embrião (Faúndes, Barzeatto, 2004; Salem, 1997). Contra a AE, aciona-se uma retórica, apoiada em fontes médico-científicas, sobre a fecundação.

A modernização do discurso católico tende a usar argumentos biomédicos para igualar o mecanismo de ação dos medicamentos misoprostol (Cytotec) e a pílula RU486 à AE. A Igreja Católica difunde a ideia de que a AE provoca "aborto químico", assim como o misoprostol e a RU486 (Pecheny, Tamburrino, 2009). Ambos têm venda proibida no Brasil ${ }^{3}$, embora o comércio ilegal do misoprostol esteja em franca expansão.

Fontes biomédicas expressivas são pouco acionadas pelos jornais para explicar o mecanismo de ação do método. Nas raras vezes em que elas são consultadas, os depoimentos editados distorcem o que esses pesquisadores relatam em suas produções científicas. Sexualidade e reprodução encontramse associadas em situações nas quais seriam desvinculadas, porém, existe uma compreensão, "alimentada" pelo catolicismo, de que todo ato sexual leva à concepção. Seguindo-se tal raciocínio, o que se usa pós-coito é abortivo (Pecheny, Tamburrino, 2009).

Artigo do colunista Ricardo Noblat de O Globo, de 04/02/08 (p.2), contrapõe-se a essa ideia. Para o autor, a Igreja Católica rejeita a AE pelo que ela não é (abortiva): "sexo e procriação são coisas indissociáveis. Sexo pelo sexo não é bem visto". Para o colunista: "Ao condená-la, o que a Igreja pretende é retardar ao máximo o que ela sabe que é inevitável: a discussão em torno da descriminalização do aborto". 


\section{Anticoncepção de emergência: mais uma "arma no arsenal" do planejamento familiar}

Consoante à terminologia da saúde pública, há um recurso às categorias bélicas, por vários interlocutores - favoráveis e contrários -, para tratar do tema. Expressões como: "arma", "arsenal", "bomba hormonal", "luta", "ofensiva", "combate", "assassinar" foram reproduzidas pelos jornais como parte dos discursos sobre a AE. O debate sobre esse método atualiza uma tradição no campo da saúde pública: transformar as ações em saúde em estratégias de "guerra".

Em depoimento do Ministro da Saúde, esse método seria mais uma "arma no arsenal" do planejamento familiar, para evitar inúmeras gestações imprevistas (sobretudo de adolescentes) e abortamentos inseguros. Notícia do jornal O Globo, de 04/01/09 (Saúde..., 04/01/2009), informa que o MS:

[...] decidiu reforçar, em 2009, a política de investimento maciço em ações de planejamento familiar. Entre os carros chefes da ofensiva, estarão a compra de 1,2 bilhão de camisinhas, um recorde em todo o mundo, e a distribuição da maior parte do estoque de 458 mil pílulas do dia seguinte [...].

Dentre os interlocutores com posição contrária à $A E$, essas expressões denotam algo explosivo, associado à ideia de "matar", "exterminar" um ser vivo, "solução covarde que mata inocentes". O método tem seu mecanismo de ação associado à morte da "criança em formação", "usar a pílula do dia seguinte é perder o apreço pela vida", e às consequências negativas para a saúde da mulher. A Igreja Católica tem construído uma retórica contra a AE centrada em premissas filosóficas, dos direitos humanos, da ética (Instituto Patrícia Galvão, 2005), que reformam velhos argumentos, dando-Ihes nova roupagem, mantendo a base dogmática de que o ato sexual tem a função única da procriação.

Essa representação da AE como algo perigoso, "medicamento forte" que precisa de cuidados na indicação e no uso, foi encontrada em estudo realizado em 2004, em quatro capitais brasileiras: Belém (PA), Salvador (BA), Curitiba (PR) e Goiânia (GO). Resultados dessa pesquisa apontam que, nos serviços públicos de saúde dessas cidades, havia cuidados especiais para armazenar e dispensar esse método (Osis et al., 2006).

A afirmação presente nos textos, de que o método é um contraceptivo "forte, bomba hormonal", com altas dosagens hormonais, uma "overdose hormonal" (Leal, 1995), pode provocar confusão entre a AE e o misoprostol.

Apesar de a mídia reproduzir divergências entre os grupos favoráveis e contrários à $A E$, de certa forma, o Estado brasileiro, assim como a Igreja Católica, não são instituições uniformes ou homogêneas. Se em alguns temas eles se antagonizam, em outros são colaboradores, pois Estado e Igreja Católica, no Brasil, mantêm relações cordiais de parceria, como no Acordo entre Brasil e Vaticano (Brasil, 2008b).

A Igreja Católica tem construído um discurso contra a AE baseado na bioética, porém, muitos termos usados pelos interlocutores católicos, editados pelos jornais, remetem ao estilo de argumentação empregado contra o aborto durante anos: "assassinar", "matar" etc. (Instituto Patrícia Galvão, 2005). O que essa instituição tenta fazer em relação à $A E$ é apresentar uma oratória centrada em premissas filosóficas, dos direitos humanos, da ética, que reformam velhos argumentos, mantendo a base dogmática de que o ato sexual deve ocorrer no ambiente do matrimônio, e não se deve evitar a concepção via métodos artificiais.

\section{"Quando os discursos se encontram": aborto como argumento central no debate sobre a anticoncepção de emergência}

Depoimentos dos interlocutores que condenam o uso da AE são publicados pelos jornais de forma a concentrar seus argumentos no mecanismo de ação do método, em uma retórica médico-científica. É possível perceber que grupos reticentes ao método se apresentam mais passionais quando recorrem a uma moral religiosa, para declarar que o método "mata" uma "vida que está começando". 
Os interlocutores favoráveis à $\mathrm{AE}$ apresentam uma argumentação menos incisiva. Em nenhum texto, o mecanismo de ação da AE é apresentado por especialista do campo científico, para contraste com as informações contrárias ao método. Os textos pouco reproduzem discursos baseados na perspectiva dos direitos reprodutivos, da AE como método que pode aumentar a autonomia das mulheres no controle da reprodução.

Alguns "temores" em relação à AE são comuns a diversos interlocutores, favoráveis ou não: a $\mathrm{AE}$ pode "provocar o aumento de DSTs e AIDS", tendo em vista que ocorre abandono do preservativo (segundo interlocutores favoráveis), e o estímulo ao sexo (conforme sujeitos contrários); é preciso cuidado com divulgação e distribuição do método, pois as mulheres podem fazer uso abusivo (regular) dele, abandonar o preservativo e outros métodos contraceptivos regulares; é preciso cuidado no uso da $A E$, pois há efeitos colaterais para a saúde feminina; o método não seria de fácil compreensão quanto a sua indicação e suas contraindicações; o uso da AE provocaria o abandono do processo de educação sexual, à medida que mulheres e homens priorizam um método contraceptivo para situações emergenciais no pós-coito; a AE seria um método para o "dia seguinte", para o "depois" da relação sexual.

Profissionais de saúde e vários atores ligados ao catolicismo apresentam ressalvas à $A E$ - fato identificado em alguns textos. As controvérsias e reações suscitadas pela questão do aborto marcam a discussão sobre a aceitabilidade de métodos contraceptivos pós-coito e que têm mecanismos de ação associados a abortamentos: DIU e AE. Há, entre os médicos, a ideia de que esses métodos provocariam "microabortos" (Faúndes et al., 2005).

Outros textos apresentam preocupação recorrente, entre os médicos, de que as mulheres não saberiam usar a $\mathrm{AE}$, abandonariam métodos contraceptivos de uso regular e abusariam do uso dele, por não compreenderem sua indicação e suas contraindicações. Em pesquisa realizada pela Febrasgo, noticiada pela Folha de S. Paulo (14/02/05), muitos médicos prescrevem a AE em seus consultórios particulares, mas não fazem isso com o público feminino que atendem nas unidades públicas de saúde. Há preconceito quanto às mulheres de classes populares: supostamente, elas desconheceriam o próprio corpo.

A mídia apresenta o discurso dos grupos favoráveis de modo pouco veemente. São reproduzidos, nos textos, argumentos pouco incisivos e esclarecedores, que não respondem aos argumentos da Igreja.

Os jornais analisados apresentam-se como instituições complexas: são influenciados por diversos interesses, cálculos institucionais e por várias relações de poder. A publicação de um texto sobre $A E$ pode envolver múltiplos fatores, alguns passíveis de observação e análise, outros obscuros para a sociedade em geral.

A mídia brasileira assume um lugar significativo na construção de uma "imagem" da AE: ora ela é tratada como um método abortivo, que pode provocar o exercício desenfreado da sexualidade feminina (tanto de mulheres adultas quanto de adolescentes); ora ela é um método eficaz na prevenção de gestações imprevistas e de abortamento.

Em síntese, no debate construído pela mídia impressa brasileira, nos últimos anos, o aborto tem sido o argumento central da discussão sobre a AE: ao buscar-se sua legitimação, invoca-se que o método poderá evitar futuros abortos inseguros, uma etapa "pré-aborto"; ao se tentar impedir sua disponibilização, oferta e utilização, a AE é considerada abortiva, porque, usada pós-coito, provocaria um "aborto químico", um "microaborto", seria o "primeiro passo para a liberação do aborto". Há um descentramento da discussão do método pós-coito como um tema em si. Um problema dessa estratégia discursiva pode ser destacado: esse fato pode dificultar o reconhecimento da $A E$, pelas potenciais usuárias, como método contraceptivo que não provoca danos a seu organismo, se corretamente usado, ou abortamentos.

A cobertura jornalística não contribui para a promoção da saúde sexual e reprodutiva: a perspectiva da autonomia feminina e dos direitos sexuais e reprodutivos pouco aparece no debate social da mídia analisada. 


\section{Agradecimentos}

A Carla Rodrigues (PUC-RJ), pela atenção, orientações e comentários críticos.

\section{Colaboradores}

Rozana Aparecida de Souza responsabilizou-se por coletar, analisar, interpretar os dados, e pela redação do artigo. Elaine Reis Brandão responsabilizou-se pela concepção do projeto, análise e interpretação dos dados; revisão crítica relevante do conteúdo intelectual; e aprovação final da versão a ser publicada.

\section{Referências}

AMATO, F. Saúde: Ministério contesta veto à pílula pós-sexo. Folha de S. Paulo, São Paulo, 17 maio 2005. Seção Cotidiano, p. C2.

AMATO, F.; CORREA, H. Saúde reprodutiva: Projetos tentam vetar pílula do dia seguinte, Folha de S. Paulo, São Paulo, 30 abril 2005. Seção Cotidiano, p. C4.

ARAÚJO, M.J.O. Painel do leitor: Pílula do dia seguinte. Folha de S. Paulo, São Paulo, 23 ago. 2005. Seção Opinião, p. A3.

BECKER, H. Métodos de pesquisa em ciências sociais. 3.ed. São Paulo: Hucitec, 1997.

BRANDÃO, E. R. Contracepção de Emergência (pílula do dia seguinte): o desafio para torná-la um dispositivo institucionalizado na rede pública de serviços de saúde no Brasil. 2008. Projeto de Pesquisa. Departamento de Medicina Preventiva/Instituto de Estudos m Saúde Coletiva/UFRJ. Rio de Janeiro.

BRASIL. Ministério da Saúde. Pesquisa nacional de demografia e saúde da criança e da mulher (PNDS, 2006). Relatório. Brasília, 2008a. 583p.

BRASIL. Acordo entre a República Federativa do Brasil e a Santa Sé Relativo ao

Estatuto Jurídico da Igreja Católica no Brasil. Cidade-Estado Vaticano, 13 de novembro de 2008b. Disponível em: <http://www2.mre.gov.br/dai/b_santa_04.htm>. Acesso em: 10 de jan. 2010.

BRASIL. Ministério da Saúde. Nota técnica sobre anticoncepção de emergência. 2006.

BRASIL. Ministério da Saúde. Coordenação de Saúde da Mulher. Assistência ao Planejamento Familiar. 3.ed. Brasília, 1996.

CAVALHEIRO, M.A. Painel do leitor: Dia Seguinte. Folha de S. Paulo, São Paulo, 04 maio 2005. Seção Opinião, p.A3.

COLLUCCI, C. EUA liberam pílula do dia seguinte sem prescrição médica. Folha de $\mathbf{S}$. Paulo, São Paulo, 25 ago. 2006. Seção Cotidiano, p. C8.

COSTA, N. F. P. et al. Acesso a anticoncepção de emergência: velhas barreiras e novas questões. Rev. Bras. de Ginecologia e Obstetrícia, v.2, n.30, p.55-60, 2008.

DENNET, D. Carnaval: Salvador dá pílula do dia seguinte à foliona. Folha de S. Paulo, São Paulo, 16 fev. 2006. Seção Cotidiano, p. C4.

DÍAZ, S.; HARDY, E.; ALVARADO, G.; EZCURRA, E. Acceptability of emergency contraception in Brazil, Chile, and Mexico. 1 - Perceptions of emergency oral contraceptives. Cad. Saúde Pública, v.5, n.19, p.1507-17, $2003 a$.

Acceptability of emergency contraception in Brazil, Chile, and Mexico. 2 -

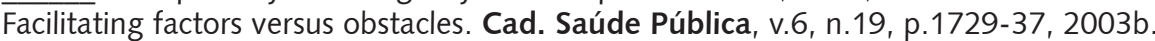


DIDES CASTILLO, C. Voces em emergencia: el discurso conservador y la pildora del dia después. Santiago, Chile: FLASCO, 2006.

DREZETT, J. Nota técnica sobre anticoncepção de emergência. Comissão de Cidadania e Reprodução, 2009. Disponível em: <http://www.ccr.org.br/ uploads/eventos/ seminarionov09/apresentacoes/NotaTecnica\%20sobre\% 20 Anticoncep\% C3\% A7\% C3\% A30\% 20de\% 20Emerg\% C3\% AAncia\% 20-\% 20 Jefferson\% 20Drezett.pdf>. Acesso em: 20 de dez. 2009.

FAÚNDES, A. et al. O papel da religiosidade na perspectiva e no agir de médicos ginecologistas em relação ao aborto previsto por lei, à anticoncepção de emergência e ao DIU. Resumo executivo. Centro de Pesquisas em Saúde Reprodutiva de Campinas - CEMICAMP. Campinas, São Paulo, 2005. Disponível em: <www.ipas.org.br/arquivos/ faundes/Resumo06.pdf>. Acesso em: 18 de ago. 2010.

FAÚNDES, A.; BARZELATTO J. O drama do aborto: em busca de um consenso. Campinas: Ed. Komedi, 2004.

FIGUEIREDO, J. Chega ao fim lua-de-mel de Bachelet no Chile. O Globo, Rio de Janeiro, 16 set 2006. Seção O Mundo/Ciência e Vida, p. 42.

FIGUEIREDO, R. Contracepção de emergência no Brasil: necessidade, acesso e política nacional. Rev. Saúde Sexual e Reprodutiva, IPAS, n.13, 2004. Disponível em: < http:// www.ipas.org.br>. Acesso em: 23 de ago. 2010.

FRANCO, B.M.; ÉBOLI, E. Saúde distribuirá 1,2 bi de camisinhas este ano, O Globo, Rio de Janeiro, 04 jan. 2009. Seção O país, p.8.

GUEDES, A.A.; CANTARINO, C. Painel do Leitor: Dia seguinte. Folha de S. Paulo, São Paulo, 11 maio 2005. Seção Opinião, p. A3.

HARDY, E. et al. Anticoncepção de emergência no Brasil: facilitadores e barreiras. Cad. Saúde Pública, v.4, n.17, p.1031-35, 2001.

HARENZA, E. Tiragem dos jornais: parte 2. Meio e mensagem on line. 18 abr. 2008. Disponível em: <http://evandroharenza.wordpress.com/2008/04/18/tiragem-dosjornais-parte-2/>. Acesso em: 03 de ago. 2010.

HUMANAE VITAE. Encíclica. Dada em Roma, junto de São Pedro, na Festa de São Tiago Apóstolo, 25 de julho de 1968. PAULUS PP. VI.

INSTITUTO PATRÍCIA GALVÃO. Pesquisa e comunicação em direitos reprodutivos: informações sobre a atuação pública de grupos contrários à legalização do aborto. São Paulo: Instituto Patrícia Galvão, 2005. 38p.

JUNG, D.M.; PACHECO, C. Painel do leitor: Dia seguinte. Folha de S. Paulo, São Paulo, 08 maio 2005. Seção Opinião, p. A3.

LEAL, O. F. Sangue, fertilidade e práticas contraceptivas. In: LEAL, O. F. (Org.). Corpo e significado: ensaios de antropologia social. Porto Alegre: Ed. UFRGS, 1995. p.15-36.

LEMOS, J. F. O risco em cena: análise das campanhas de prevenção à AIDS da MTV Brasil. 2006. Dissertação (Mestrado) - Instituto de Medicina Social da Universidade Estadual do Rio de Janeiro, IMS/UERJ, Rio de Janeiro.

LORES, R. J. Bachelet enfrenta Igreja por pílula do dia seguinte. Folha de S. Paulo, São Paulo, 12 set. 2006. Seção Mundo, p. A12.

LUPTON, D. Femininity, responsibility, and the technological imperative: discourses on breast cancer in the Australian press. Intern. Journal of Health Serv., v.1, n.24, p.73-89, 1994.

Discourse analysis: a new methodology for understanding the ideologies of health and illness. Austr. Journal of Public Health, v.2, n.16, p.145-50, jun. 1992. 
LUPTON, D.; MCLEAN, J. Representing doctors: discourses and images in the Australian press. Social Science Medicine, v.8, n.46, p.947-58, 1998.

MARTIN, A. La anticoncepción de emergencia em América Latina y el Caribe. Rev. Panam. de Salud Pública, v.6, n.16, p.424-31, 2004.

MINAYO, M. C. S. O desafio do conhecimento: pesquisa qualitativa em saúde. 11.ed. Rio de Janeiro/São Paulo: Hucitec-Abrasco, 2008.

NOBLAT, R. Sobras da Folia / Coluna Ricardo Noblat. O Globo, Rio de Janeiro, 04 fev. 2008 , p. 2.

OSIS, M. J. D et al. Atenção ao planejamento familiar no Brasil hoje: reflexões sobre os resultados de uma pesquisa. Cad. Saúde Pública, v.11, n.22, p.2481-90, 2006.

PECHENY, M.; TAMBURRINO, M. C. ¿“La palabra lo dice"? Interpretaciones cruzadas y obstáculos al acceso a la anticoncepción de emergencia. Sexualidad, Salud y Sociedad Rev. Latinoamericana, s/v, n. 1, p.158-76, 2009.

RANGEL, R. Saúde vai financiar $100 \%$ do planejamento familiar. O Globo, Rio de Janeiro, 29 jan. 2005. Seção O País, p. 9.

SALEM, T. As novas tecnologias reprodutivas: o estatuto do embrião e a noção de pessoa. MANA, v.1, n.3, p.75-94, 1997.

SILVA, M.S. Painel do leitor: Solução covarde. Folha de S. Paulo, São Paulo, 21 maio 2005. Seção Opinião, p.A3.

SOUZA, R. A. O debate social sobre a Anticoncepção de Emergência no Brasil (2005-2008). 2010. Dissertação (Mestrado) - Instituto de Estudos em Saúde Coletiva da Universidade Federal do Rio de Janeiro, IESC/UFRJ, Rio de Janeiro

SOUZA, R. A; BRANDÃO, E. R. Marcos normativos da anticoncepção de emergência e as dificuldades de sua institucionalização nos serviços públicos de saúde. PHYSIS: Rev. Saúde Coletiva, v.14, n.19, p.1067-86, 2009.

SUWWAN, L. Ministério amplia a distribuição gratuita da pílula do dia seguinte. Folha de S. Paulo, sucursal de Brasília, 14 fev. 2005, página C2.

VICTORA, C. et al. Pesquisa qualitativa em saúde: uma introdução ao tema. Porto Alegre: Tomo Editorial, 2000.

VIDAL, R.A. Painel do leitor: Dia seguinte. Folha de S. Paulo, São Paulo, 23 maio 2005. Seção Opinião, p. A3

VIEIRA, A. G. Onde estão as pílulas do prefeito? O Globo, Rio de Janeiro, 06 out. 2005. Seção Opinião/Tema em Debate: Direitos civis, p. 7. 
SOUZA, R.A.; BRANDÃO, E.R.

SOUZA, R.A.; BRANDÃO, E.R. A la sombra del aborto: el debate social sobre la anticoncepción de emergencia en la prensa escrita brasileña (2005-2009) Interface Comunic., Saude, Educ., v.16, n.40, p.161-75, jan./mar. 2012.

Esta investigación socioantropológica discute premisas centrales del debate sobre la Anticoncepción de Emergencia (AE) en Brasil, mediante análisis de 131 textos publicados en los periódicos Folha de S. Paulo y O Globo de Rio de Janeiro, de 2005 a 2009, orientada por los descriptores: píldora del día siguiente, contracepción de emergencia y AE. La iglesia católica y el Ministerio de Salud con los principales interlocutores. Se identifica un discurso basado en metáforas bélicas, consonante con la terminología de la salud pública. Argumentos de defensa de los derechos sexuales y reproductivos son escasos. La Iglesia, fundamentada en argumentos biomédicos, considera la AE una práctica abortiva por ser utilizada pos-coito, equiparándola al misoprostol (Cytotec) y a la píldora RU486. Ministerio y profesionales de salud defiendem que AE puede evitar abortos inseguros, pero su mecanismo de acción no es bien discutido, entretanto el tema del aborto figura como central.

Palabras clave: Anticonceptivos poscoito. Aborto. Derechos sexuales y reproductivos. Servicios de salud.

Recebido em 07/11/2010. Aprovado em 08/04/2011. 
